\title{
¿ARTÍCULO 17 DE LA CONSTITUCIÓN COMO OPCIÓN AL ORDEN JURÍDICO?*
}

\author{
Luis Miguel DíAZ**
}

RESUMEN: En el contexto del nuevo artículo 17 de la Constitución Política, que incorpora el derecho a mecanismos alternativos de solución de controversias, el artículo presenta referencias legislativas que precedieron a la enmienda constitucional; y un panorama de tratados y leyes mexicanas que contienen preceptos sobre dichos mecanismos. Inicia con una introducción sobre una nueva manera de enfocar los conflictos legales y termina con reflexiones sobre el futuro desarrollo de los mecanismos alternativos de solución de controversias.

ABSTRACT: This article presents legislative references prior to the Constitution's amendment, the panorama of treaty and the Mexican laws that include precepts on those mechanisms, all this in the frame of the new article 17 of the Constitution, which incorporates the right to alternative methods of dispute settlement. It begins with an introduction about a new way to focus on the legal conflicts and ends with reflections about the future development of those alternative methods of dispute settlement.

RÉSUMÉ: En vertu du nouvel article 17 de la Constitution, qui prévoit le droit à la résolution extrajudiciaire des litiges, l'article fait référence à la législation qui précédaient l'amendement de la Constitution, une image des traités et la législation mexicaine qui contenait des dispositions relatives à ces mécanismes. Commence par une introduction à une nouvelle façon d'aborder les conflits et se termine par une réflexion sur l'avenir de la résolution extrajudiciaire des litiges.

* Artículo recibido el 29 de julio de 2008 y aceptado para su publicación el 4 de septiembre de 2008. Este artículo fue elaborado como una contribución al libro El nuevo artículo 17 constitucional: Acceso alternativo a la justicia. Una visión de conjunto sobre los mecanismos alternativos de solución de controversias, coordinado por Gonzalo Uribarri Carpintero.

** Licenciado en derecho por la UNAM y doctor en ciencias jurídicas de la Harvard Law School. Presidente del Centro Interdisciplinario para el Manejo de Conflictos, A. C. 
SUMARIO: I. Nota introductoria. II. Bosquejo de mecanismos alternativos de solución de controversias. III. Factor humano en los mecanismos alternativos de solución de controversias. IV. Desaprender la necesidad del litigio como respuesta al conflicto. V. Derecho internacional de los mecanismos alternativos de solución de controversias. VI. Derecho mexicano sobre los mecanismos alternativos de solución de controversias. VII. El futuro de los mecanismos alternativos de solución de controversias.

\section{NOTA INTRODUCTORIA}

Históricamente el manejo de conflictos en las sociedades ha respondido a dos modelos, aparentemente excluyentes y en ocasiones complementarios. En uno, quienes tienen el conflicto lo manejan por sí mismos. En el otro una autoridad resuelve los conflictos.

El texto original de la Constitución adoptó el sistema de que los conflictos deben ser resueltos por autoridades. Estableció la regla de que ninguna persona podría hacerse justicia por sí misma y que los tribunales administrarían la justicia.

Sin embargo, la reforma al artículo 17 de la Constitución de 2008 al ordenar que las leyes preverán mecanismos alternativos de solución de controversias establece la posibilidad de que las personas puedan resolver sus conflictos sin autoridades como un mecanismo complementario al servicio de la justicia ordinaria. ${ }^{1}$

Esta nueva opción constitucional significa que debemos desaprender la creencia de que frente a un conflicto, la única y mejor opción es que un tribunal judicial intervenga. La iniciativa dictaminada en la Cámara de Senadores en conjunto con la minuta de la Cámara de Diputados, respecto a las propuestas de modificación del artículo 17, indicó: Se adiciona un último párrafo para que los mecanismos alternativos de solución de controversias sean eje toral del sistema de justicia en general y, por supuesto, del penal. ${ }^{2}$

1 Diario Oficial de la Federación. Decreto que modifica la Constitución del 18 de junio de 2008. http://www.diputados.gob.mx/LeyesBiblio/ref/dof/CPEUM_ref_180_18jun 08.doc.

2 http://www.diputados.gob.mx/LeyesBiblio/legis/reflx.htm. 
El Libro blanco de la reforma judicial, que resultó de la Consulta Nacional para una Reforma Integral y Coherente sobre el Sistema de Impartición de Justicia en el Estado Mexicano, realizado por la Suprema Corte de Justicia de la Nación de 2003 a 2005, anticipó la inclusión de los mecanismos alternativos, aunque utilizó otra terminología: en el tema legislativo, parece necesario revisar la terminología empleada y tratar de uniformarla. Incluso hay propuestas que se inclinan por reformar el artículo 17 de la Constitución a fin de incorporar el derecho a la justicia alternativa. ${ }^{3}$

La inclusión en la Constitución de los mecanismos alternativos de solución de controversias constituye también un paso para fortalecer a la democracia, al privilegiar la participación de voluntades privadas en el manejo de sus conflictos; y así convertir dicha opción en un derecho de las personas para decidir por sí mismas sus conflictos, sin la tutela de órganos del Estado.

\section{BOSQUEJO DE MECANISMOS ALTERNATIVOS DE SOLUCIÓN DE CONTROVERSIAS}

En la tradición jurídica, la expresión de mecanismos alternativos de solución de controversias ha servido para significar mecanismos para resolver conflictos que no requieren autoridades judiciales.

De los mecanismos alternativos de solución de controversias, sólo en el arbitraje una tercera persona distinta a las partes decide la disputa. El árbitro o tribunal arbitral sigue un procedimiento legal y decide conforme a reglas jurídicas o con base en principios de equidad, si las partes así lo autorizaron. ${ }^{4}$

3 Libro blanco de la reforma judicial. Una agenda para la justicia en México, México, SCJN. http://www.scjn.gob.mx/PortalSCJN/RecJur/ReformaJudicial/LibroBlancoRe formaJudicial/.

4 Una explicación sencilla, amena y ordenada de la regulación del arbitraje en México en Uribarri, Gonzalo, Derecho arbitral mexicano, México, Porrúa, 2006. Un panorama del arbitraje en México en Cruz Miramontes, Rodolfo y Cruz Barney, Óscar, El arbitraje. Los diversos mecanismos de solución de controversias: análisis y práctica en México, México, Porrúa, 2004. Sobre textos de arbitraje en Díaz, Luis Miguel, Arbitraje: privatización de la justicia, 3a. ed., México, Themis, 2004. En arbitraje en comercio, Graham, Luis Enrique, El arbitraje comercial, México, Themis, 2000, y Pereznieto, Leonel (comp.), Arbitraje comercial internacional, México, Fontamara, 2002. 
En todos los demás mecanismos alternativos de solución de controversias, las partes del conflicto deciden por sí mismas. En la negociación las partes lo hacen directamente; en la conciliación o mediación una tercera persona asiste a las partes a que ellas decidan, pero las partes siempre controlan el proceso y su resultado. El tercero que asiste a las partes en conflicto no tiene autoridad para imponer una solución negociada.

Respecto a la efectividad de los mecanismos alternativos de solución de controversias, estadísticamente, cerca del $90 \%$ de los casos en que las partes optan por dichos mecanismos para terminar un conflicto, el resultado es una solución negociada satisfactoria para ambas partes. La inmensa mayoría de las soluciones negociadas se cumplen.

\section{FACTOR HUMANO EN LOS MECANISMOS ALTERNATIVOS DE SOLUCIÓN DE CONTROVERSIAS}

Todos podemos solucionar conflictos o ayudar a que otros los solucionen, ya que no requerimos de conocimientos especializados para ello. Dicha actividad no está reservada a los especialistas, y las reglas fundamentales de convivencia social se aprenden en los primeros años de socialización del ser humano.

En consecuencia, mediar o negociar para resolver conflictos es algo en que todos hemos participado, participamos y seguiremos participando. En nuestra propia biología se encuentra las aptitudes para interactuar con los demás. ${ }^{5}$

Toda generalización sobre los mecanismos alternativos de solución de controversias debe tener excepciones, puesto que cada cabeza humana y cada situación son únicas. Por ello proponer un mecanismo que en todos los casos y bajo cualquier circunstancia sea pertinente sería un engaño. Así, una manera eficaz de abordar los mecanismos alternativos de so-

5 En mi artículo "Privatización de conflictos", El Foro, Barra Mexicana Colegio de Abogados, t. X, núm. 1, 1997, pp. 55-96 y en mi libro Moralejas para mediar y negociar, Themis, 2004, desarrollo la hipótesis de que estamos evolutivamente condicionados para el manejo de conflictos en sociedades pequeñas, no urbanas. En mi libro Manejo de conflictos desde la sabiduría del cine y las sanciones, más Chaplin y menos Platón, México, Pax, 2005, pondero el recurso a imágenes más que a explicaciones para reconocer y utilizar nuestras habilidades para negociar y manejar conflictos. 
lución de controversias se sustenta en ser flexible y en desaprender lo que no funciona.

Los mecanismos alternativos de solución de controversias giran en función del lenguaje como medio para comunicarse. Por ello, el aprender a usar el lenguaje verbal y corporal, y la entonación es fundamental.

Un factor que puede ser decisivo para lograr el acuerdo para terminar un conflicto es la confianza de las partes en los mecanismos alternativos de solución recontroversias y el seguir los rituales apropiados. Los ritos para preparar y tomar decisiones convalidan los acuerdos y promueven la resolución efectiva de problemas personales y sociales.

Cuando las partes de un conflicto no pueden acordar su solución directamente, una tercera persona independiente (mediador/conciliador/facilitador) puede tender puentes de comunicación entre las partes, escuchar sus versiones, contextualizarlas, propiciar procesos, allegar información, y sugerir propuestas de solución. Ella o él pueden o no ser abogados. En ocasiones se utiliza la co-mediación cuando dos o más asisten al arreglo.

La hipótesis efectiva de los mecanismos alternativos de solución de controversias descansa en una nueva manera de pensar sobre los conflictos y en dos presupuestos.

a) Que las partes realmente desean una solución a su conflicto.

b) Que las partes prefieren decidir y no que otros decidan su conflicto.

\section{DESAPRENDER LA NECESIDAD DEL LITIGIO COMO RESPUESTA AL CONFLICTO}

Cuando existe un conflicto legal tradicionalmente la respuesta automática es pensar como única opción el recurrir a un abogado para que atienda el asunto en tribunales. Hay que desaprender este prejuicio.

En los procesos jurisdiccionales nadie tiene control total sobre el proceso ni sobre el resultado. Existe incertidumbre. El recurso a tribunales generalmente deja insatisfechas a una o ambas partes y genera angustia. El derecho procesal es la ritualización de las guerras, donde unos ganan y otros pierden, o todos pierden y en donde se inhibe la comunicación personal. Por todo lo anterior, es necesario desaprender la necesidad de tribunales y aprender a utilizar los mecanismos alternativos de solución de controversias. 
El punto de partida es que el cerebro humano registra mejor aquello que aprende a partir de desaprender. Para aprender el acierto hay que desaprender el error. El pensamiento sobre la necesidad de los tribunales llena el espacio del error, hay que colocarse en el lado del error para de allí moverse al espacio del acierto que es el recurso a los mecanismos alternativos de solución de controversias.

El motivo y sentido de la metáfora de desaprender el error y aprender el acierto son recogidos en el Libro blanco cuando reconoce los cambios que implica el insertar los mecanismos alternos para la solución de conflictos o justicia alternativa en el contexto de la justicia ordinaria:

No pueden dejar de mencionarse los problemas técnicos que surgen con motivo del empleo de la justicia alternativa. En este sentido, los poderes judiciales del país deben revisar sus experiencias en la ejecución de sus programas de justicia alternativa y proponer las reformas legislativas que se estimen necesarias. En particular, parece necesario legislar sobre cuestiones como el carácter voluntario de la justicia alternativa, la confidencialidad en la mediación y el reconocimiento de los convenios. ${ }^{6}$

\section{DERECHO INTERNACIONAL DE LOS MECANISMOS ALTERNATIVOS DE SOLUCIÓN DE CONTROVERSIAS}

\section{Negociación y mediación en el derecho internacional público}

En 1919 con el Tratado de Versalles, que puso fin a la Primera Guerra Mundial, por primera vez se reglamentó la guerra. ${ }^{7}$ A partir de 1929 con el Tratado General para la Renuncia a la Guerra se prohibió el recurso a la fuerza como medio legítimo para resolver controversias. ${ }^{8}$ En este tratado, conocido también como Pacto Briand Kellogg o Pacto de París, los Estados convinieron en nunca solucionar sus disputas o conflictos de

6 http://www.scjn.gob.mx/PortalSCJN/RecJur/ReformaJudicial/LibroBlancoRefor maJudicial/.

7 Los artículos 11-15 del Protocolo establecían el compromiso de no recurrir a la guerra en tanto no se hubieran agotado los procedimientos pacíficos. Véase Manual sobre el arreglo pacífico de controversias entre Estados, Nueva York, Oficina de Asuntos Jurídicos. División de Codificación. Naciones Unidas, 1992, OLA/COD/2416.

8 Firmado en París el 27 de agosto de 1928. 
cualquier naturaleza y origen por medio de la guerra, sino sólo por medios pacíficos.

A partir del Pacto de París la solución a los conflictos, además de que debe ser siempre por la vía pacífica, debe procurar que las partes tengan una comunicación constante, amigable y razonable. ${ }^{9}$ Gobiernos e instituciones privadas internacionales han plasmado en distintos instrumentos jurídicos internacionales la necesidad de agotar la negociación y consultas entre las partes, antes de acudir a cualquier medio litigioso de solución de controversias como es el arbitraje.

En el marco de las Naciones Unidas establecidas en la Carta de San Francisco en 1945, el artículo 33 de la Carta de la ONU indica:

1. Las partes en una controversia cuya continuación sea susceptible de poner en peligro el mantenimiento de la paz y la seguridad internacionales tratarán de buscarle solución, ante todo, mediante la negociación, la investigación, la mediación, la conciliación, el arbitraje, el arreglo judicial, el recurso a organismos o acuerdos regionales u otros medios pacíficos de su elección.

2. El Consejo de Seguridad, si lo estimare necesario, instará a las partes a que arreglen sus controversias por dichos medios. ${ }^{10}$

La Corte Internacional de Justicia de La Haya declaró que: no es necesario insistir en el carácter fundamental de las negociaciones como método para resolver conflictos. ${ }^{11}$

9 Aprobado por el Senado el 23 de octubre de 1929. Publicado en el Diario Oficial del 24 de diciembre de 1929. Texto en Colección de Tratados Celebrados por México, Senado y SRE, t. V (1924-1928), pp. 723-725. Son Estados parte los siguientes: Afganistán, Albania, Antigua y Barbuda, Australia, Austria, Barbados, Bélgica, Brasil, Bulgaria, Canadá, Chile, China, Colombia, Costa Rica, Cuba, Checoslovaquia (ahora Estados sucesores), Dinamarca, Dominica, República Dominicana, Ecuador, Egipto, Estonia, Etiopía, Fiji, Finlandia, Francia, Alemania, Grecia, Guatemala, Haití, Honduras, Hungría, Islandia, India, Irán, Irak, Irlanda, Italia, Japón, Latvia, Liberia, Lituania, Luxemburgo, México, Países Bajos, Nueva Zelanda, Nicaragua, Noruega, Panamá, Paraguay, Perú, Polonia, Portugal, Rumania, Arabia Saudita, Eslovenia, Sudáfrica, España, Suecia, Suiza, Tailandia, Turquía, Unión de Repúblicas Socialistas Soviéticas, Reino Unido, Estados Unidos, Venezuela y Yugoslavia (ahora Estados sucesores). Véase México: relación de tratados en vigor, México, SRE, 1996 pp. 135 y 136.

10 Firmada por México el 26 de junio de 1945 en San Francisco, publicada en el Diario Oficial de la Federación del 17 de octubre de 1945.

11 ICJ Reports 1969, p. 48, párrafo 86. 
En la Declaración de Manila sobre el Arreglo Pacífico de Controversias Internacionales se reconoció a las negociaciones directas como un medio flexible y eficaz que las partes deberán tomar en cuenta al escoger un método para llegar a un arreglo efectivo y pronto de su conflicto. ${ }^{12}$

En los tratados, la palabra diplomacia se usa como sinónimo de negociación. ${ }^{13}$ Las negociaciones bilaterales por lo general se realizan directamente entre delegaciones o representantes debidamente designados por sus gobiernos. Aunque formalmente los negociadores suelen ser ministros o funcionarios de los ministerios de relaciones exteriores de las partes, en realidad muchas controversias se resuelven por negociadores especializados. Existen casos en que los jefes de Estado o de gobierno inician las negociaciones y posteriormente se desarrollan a un nivel jerárquico inferior o de expertos. En ocasiones es a la inversa, es decir, los jefes de Estado participan sólo para concluir las negociaciones. Las misiones diplomáticas permanentes juegan un papel determinante en la presentación de la postura de sus respectivos gobiernos en las negociaciones con el ministerio de relaciones exteriores del Estado en el que están acreditadas.

Cuando en un conflicto los Estados partes no tienen relaciones diplomáticas, parece conveniente que las negociaciones para resolver la controversia se lleven a cabo en un tercer Estado o a través de sus misiones permanentes ante la ONU.

En algunos casos se puede encargar a particulares que fueron prominentes funcionarios públicos o académicos, la preparación del terreno para las negociaciones propiamente dichas o para que sean ellos los negociadores.

Las negociaciones plurilaterales tienen lugar cuando varios estados son partes en una misma controversia. Una conferencia internacional puede ofrecer el marco para el proceso de negociación. Se han dado casos en que una de las partes convoca a una conferencia en la que una o varias partes en la controversia se abstuvieron de participar. Cuando esto sucede no es posible que se den las negociaciones.

12 Declaración de Manila en A/Res. 37/10, del 15 de noviembre de 1982. Texto en español en Gutiérrez Espada, Cesáreo y Calvo Caravaca, Alfonso Luis, Textos de derecho internacional público, Madrid, Tecnos, 1986, pp. 817-821. Véase también Ortiz Ahlf, Loretta, Derecho internacional público, México, Harla, 1993.

13 Artículo 36, Draft Convention on the Law of Treaties, American Journal of International Law, Supplement. Part III, Law of Treaties, vol. 29, 1935, p. 665. 
Los Estados que no son parte en un conflicto pero tienen interés en que éste se solucione, pueden crear un grupo de amigos para analizar la controversia y proponer soluciones a la misma, aunque las partes en conflicto no participen. En caso de que éstas acepten dichas soluciones, tales grupos habrán contribuido al arreglo de la disputa.

Las negociaciones colectivas en el marco de una organización internacional son cada día más frecuentes. La Corte Internacional de Justicia ha señalado el reconocimiento y eficacia de la diplomacia mediante conferencia como una de las formas establecidas de negociación internacional:

La diplomacia mediante conferencia o la diplomacia parlamentaria ha llegado a ser reconocida en los últimos cuatro o cinco decenios como una de las formas establecidas de negociación internacional. En los casos en que las cuestiones controvertidas son de interés común para un grupo de Estados de un lado u otro en una entidad organizada, la diplomacia parlamentaria o de conferencia ha resultado ser con frecuencia la forma más práctica de negociación. ${ }^{14}$

En las negociaciones bilaterales o en las plurilaterales, lo común es que se realicen alternativamente en cada una de las capitales o, en caso de ser países vecinos, en una localidad próxima a la frontera común. También se pueden llevar a cabo en una o varias ciudades situadas fuera de los territorios respectivos de las partes en conflicto.

Las negociaciones colectivas en el seno de una organización internacional pueden celebrarse en la sede de la organización o en otro lugar, siempre que el órgano que tenga competencia en la esfera del arreglo pacífico de las controversias así lo decida.

En las negociaciones bilaterales, las partes son las que deciden el grado de publicidad que desean dar a sus negociaciones. Las negociaciones bilaterales que han sido alentadas por organizaciones internacionales pueden ser objeto de un cierto grado de publicidad. Las negociaciones que se realizan en el seno de un órgano de una organización internacional, al menos en parte, se llevan a cabo en público y se consignan en documentos oficiales. Sin embargo, cada vez se realizan más negociaciones colectivas en privado y de manera no oficial. 
El proceso de negociación, según las circunstancias, puede durar desde minutos hasta decenios, incluso de manera intermitente. Sin embargo, en algunos tratados se fija un plazo dentro del cual se debe terminar la negociación. Si ésta no ha dado frutos, se podrá recurrir a otro medio de arreglo pacífico.

Varios tratados establecen la obligación expresa para las partes de adoptar una actitud positiva al celebrar consultas encaminadas a resolver las controversias derivadas de la interpretación o aplicación del tratado. ${ }^{15}$

Esta idea se expresa también en la Declaración de Manila, en la que se dispone que cuando los Estados opten por las negociaciones directas, deberían negociar efectivamente a fin de llegar a un pronto arreglo aceptable para las partes. ${ }^{16}$ Este precepto reitera en el contexto específico de la negociación la idea en virtud de la cual los Estados procurarán, de buena fe y con un espíritu de cooperación, el arreglo pronto y equitativo de sus controversias internacionales por cualquiera de los medios siguientes. ${ }^{17}$

También en las resoluciones de órganos de las organizaciones internacionales en las que se pide a los Estados partes en una controversia que entablen negociaciones, se ha subrayado la necesidad de que todos los interesados adopten una actitud positiva con miras a solucionar el conflicto.

El fallo de la Corte Internacional de Justicia en África sudoccidental (objeciones preliminares) indicó: "lo que importa no es tanto la forma de la negociación como la actitud y las posiciones de las Partes sobre los temas de fondo de la cuestión de que se trata. Mientras ambas Partes mantengan posiciones inflexibles... no hay razón para pensar que la controversia pueda resolverse por nuevas negociaciones entre las Partes". ${ }^{18}$

15 Por ejemplo, el procedimiento previsto por la Organización Mundial del Comercio (OMC) para resolver los desacuerdos comerciales en el marco del Entendimiento sobre solución de diferencias. Se plantea una diferencia cuando un gobierno miembro considera que otro gobierno miembro está infringiendo un acuerdo o un compromiso que había contraído en el marco de la OMC. Los acuerdos de la OMC son obra de los propios gobiernos miembros: los acuerdos son el resultado de las negociaciones de los miembros. La responsabilidad de las soluciones recae en última instancia en los gobiernos miembros a través del órgano de solución de diferencias. http://www.wto.org/spanish/tratop_s/dis pu_s/dispu_s.htm\#top.

16 Sección 1, párrafo 10.

17 Sección 1, párrafo 5.

18 ICJ Reports 1962, p. 346. 
Asimismo, la Corte, en su fallo en Plataforma continental del Mar del Norte declaró:

Las Partes están obligadas a entablar negociaciones con miras a llegar a un acuerdo y no simplemente pasar por un proceso formal de negociación como una especie de condición previa para la aplicación automática de un determinado método de delimitación a falta de acuerdo; están obligadas a conducirse de manera que las negociaciones sean significativas, lo que no sucederá si cualquiera de ellas insiste en su propia posición sin prever ninguna modificación de la misma. ${ }^{19}$

Aunque las medidas encaminadas a facilitar el proceso de negociación pueden ser tomadas conjuntamente por las partes sin que participe un tercero, los órganos de la ONU o de otras organizaciones internacionales pueden facilitar el proceso de negociación poniendo a disposición de las partes los servicios de un tercero o recomendando que las partes se pongan de acuerdo para nombrar a una persona ajena a la controversia para que preste su asistencia al proceso de negociación.

En este sentido, dentro de las facultades del Consejo de Seguridad están las de recomendar los procedimientos o métodos de ajuste que sean apropiados ${ }^{20}$ recomendar los términos de arreglo que (el Consejo de Seguridad) considere apropiado, ${ }^{21} \mathrm{y}$ hacer recomendaciones a las partes a efecto de que se llegue a un arreglo pacífico. ${ }^{22}$

La Asamblea General tiene la facultad de recomendar medidas para el arreglo pacífico de cualesquiera situaciones, sea cual fuere su origen, que a juicio de la Asamblea puedan perjudicar el bienestar general o las relaciones amistosas entre naciones, incluso las situaciones y resultantes de una violación de las disposiciones de esta Carta que enuncian los Propósitos y Principios de las Naciones Unidas, ${ }^{23}$ salvo que el Consejo de Seguridad esté desempeñando las funciones que le asigna esta Carta con respecto a una controversia o situación ${ }^{24}$ y que no lo solicite dicho Consejo.

19 ICJ Reports 1969, p. 47.

20 Artículo 36 (1) de la Carta de las Naciones Unidas.

21 Artículo 37 (2) de la Carta de las Naciones Unidas.

22 Artículo 38 de la Carta de las Naciones Unidas.

23 Artículo 14 de la Carta de las Naciones Unidas.

24 Artículo 12 (1) de la Carta de las Naciones Unidas. 
Entre las funciones del secretario general de la ONU, en cuanto al arreglo pacífico de controversias, figuran las siguientes: comunicaciones, que comprenden gestiones y llamamientos; conversaciones y consultas con las partes; actividades de determinación de los hechos; participación en las negociaciones encaminadas al arreglo de una controversia o a la ejecución de un arreglo convenido, o prestación de asistencia a esas negociaciones. ${ }^{25}$

La existencia de negociaciones no debe impedir el examen de una controversia. Sobre este tema, la Corte Internacional de Justicia declaró, en Plataforma Continental del Mar Egeo, que no podía compartir la opinión de que no debía seguir adelante con el asunto mientras las partes continuaran negociando y de que la existencia de negociaciones activas en curso constituía un impedimento al ejercicio de la jurisdicción de la Corte.

Además, declaró:

Las negociaciones y el arreglo judicial se enumeran juntos en el artículo 33 de la Carta de las naciones Unidas como medio para el arreglo pacífico de las controversias. La jurisprudencia de la Corte ofrece varios ejemplos de asuntos en los que las negociaciones y el recurso al arreglo judicial se han desarrollado pari passu. Varios asuntos muestran que los procedimientos judiciales pueden interrumpirse cuando tales negociaciones conducen a la solución de la controversia. En consecuencia, el hecho de que se realicen activamente negociaciones durante las presentes actuaciones judiciales no constituye legalmente obstáculo alguno al ejercicio por la corte de su función judicial. ${ }^{26}$

\section{Tratado de Libre Comercio de América del Norte}

El TLCAN contiene varios mecanismos alternativos para la solución de controversias. ${ }^{27}$

25 Véase Repertorio de la práctica de los Órganos de las Naciones Unidas, Suplemento núm. 3, vol. IV, artículos 97-101 de la Carta de las Naciones Unidas, 1973, pp. 145-152; también A/44/959, S/21274, A/44/344/Add.1, A/44/886, S/21029, y Documentos Oficiales de la Asamblea General, cuadragésimo quinto periodo de sesiones, Suplemento núm. $1(\mathrm{~A} / 45 / 1)$.

26 ICJ Reports 1980, p. 24, párrafo 43.

27 Son partes Canadá, Estados Unidos y México. Publicado en el Diario Oficial el 20 de diciembre de 1993. Entró en vigor el 1o. de enero de 1994. También en la Colec- 
En el capítulo XI sobre inversión se estableció un novedoso mecanismo para la solución de controversias en materia de inversión entre una parte y un inversionista de otra parte. Se acordó que las partes contendientes intentarán primero dirimir la controversia en materia de inversión por vía de consulta o negociación. ${ }^{28}$

El capítulo XIX prevé un mecanismo de consultas entre las partes para examinar cualquier problema que resulte de la ejecución u operación de este capítulo y para recomendar soluciones cuando corresponda. En el caso de que una parte adopte reformas legislativas o reglamentarias que perjudiquen a la otra, ésta podrá solicitar la formación de un panel binacional, el cual emitirá una opinión declarativa. En caso de que exista alguna inconformidad con esta opinión, se seguirá un proceso de consultas entre las partes que busca que la parte que adoptó dichas reformas rectifique su conducta. ${ }^{29}$

En el capítulo XX se prevén los mecanismos alternativos para la solución de controversias de consultas, negociaciones, buenos oficios, la conciliación y el arbitraje. Si no se resuelve el asunto conforme a las consultas entre las partes, cualquiera de ellas podrá solicitar a la Comisión de Libre Comercio, la cual se avocará a la solución de la controversia. La Comisión podrá recurrir a los buenos oficios, la conciliación, la mediación como mecanismos alternativos para la solución de controver-

ción de tratados celebrados por México, México, Senado-SRE, t. XXXV, 1992, pp. 5-689; t. XXXVI, 1992, pp. 691-1386; t. XXXVII, 1992, pp. 1387-1925. Texto completo en http://www.nafta-sec-alena.org/DefaultSite/index_s.aspx?DetailID $=628$. Un excelente análisis del desempeño de los mecanismos alternativos de solución de controversias y promoción del TLCAN y sus acuerdos paralelos en su primera década en Vega, Gustavo et al., México, Estados Unidos y Canadá: resolución de controversias en la era post Tratado de Libre Comercio de América del Norte, México, UNAM, 2005; Díaz, Luis Miguel y Garza, Antonio, "Los mecanismos para la solución de controversias del Tratado de Libre Comercio de América del Norte", Revista Investigaciones Jurídicas, 1993, pp. 71-94; Díaz, Luis Miguel y Oretskin, N., "Mediation Furthers the Principles of Transparency and Cooperation to Solve Disputes in the NAFTA Free Trade Area", Denver Journal of International Law \& Policy Issue, 30, núm. 2, 2002, pp. 73-89.

28 Artículo 1118, sección B del capítulo XI, y artículo 1120.

29 Cruz Barney, Óscar, Solución de controversias y antidumping en el Tratado de Libre Comercio de América del Norte, México, Porrúa, 2002. 
sias para apoyar a las partes consultantes a lograr una solución mutuamente satisfactoria de la controversia. ${ }^{30}$

Sistema similar ocurre con el Acuerdo Paralelo de Cooperación Ambiental (ACAAN). ${ }^{31}$ Dentro de las medidas que las partes se comprometieron a llevar a cabo con el objeto de aplicar de manera efectiva sus leyes y reglamentos ambientales, así como de lograr altos niveles de protección del ambiente, es la de proveer o alentar el uso de servicios de mediación. ${ }^{32}$

El ACAAN reconoce que para realizar los objetivos ambientales del TLCAN, es preciso prevenir o evitar las controversias, y en su caso resolverlas de manera conjunta entre las partes, tratando de evitar que la controversia la decida otra persona distinta a ellas. Asimismo, en caso de haber desacuerdo sobre la interpretación y la aplicación del ACAAN, las partes procurarán en todo momento lograr un consenso sobre el tema y harán su mayor esfuerzo por resolver, mediante cooperación y consultas, cualquier asunto que pudiera afectar el funcionamiento de dicho acuerdo. ${ }^{33}$

Al respecto, también se dispone que cuando una parte solicite consultas con cualquiera otra parte sobre la existencia de una pauta persistente de omisiones en la aplicación efectiva de la legislación ambiental de esa otra parte, ambas harán todo lo posible por alcanzar una solución mutuamente satisfactoria del asunto a través de las consultas entre ellas. ${ }^{34} \mathrm{Si}$ por medio de estas consultas no logran resolver su diferencia, cualquier parte podrá solicitar una sesión extraordinaria del Consejo. Éste ayudará a las partes a alcanzar una solución mutuamente satisfactoria de la controversia y podrá recurrir a los buenos oficios, la conciliación, la mediación o a otros procedimientos de solución de controversias. $^{35}$

30 Artículo 2007.

31 Firmado en las ciudades de México, Ottawa y Washington, D. C., el 14 de septiembre de 1993. Colección de tratados celebrados por México, México, Senado-SRE, t. XXXVII, 1992, pp. 1927 y 1979.

32 Artículo 5 (1) h.

33 Artículo 20 (1).

34 Artículo 22.

35 Artículo 23 (1). 
Si el Consejo no resuelve la controversia, podrá convocar a un panel arbitral para examinar el asunto. ${ }^{36}$ Aun cuando el panel haya determinado en su informe final que ha habido una pauta persistente de omisiones de la parte demandada en la aplicación efectiva de su legislación ambiental, las partes puedan acordar un plan de acción mutuamente satisfactorio, ${ }^{37}$ el cual, por lo regular, se ajustará a las determinaciones y recomendaciones del panel.

En el preámbulo del Acuerdo de Cooperación Laboral (ACLAN) los gobiernos reconocen que para promover el desarrollo económico basado en altos niveles de capacitación y productividad en América del Norte, es necesario el fortalecimiento de la cooperación obrero-patronal, a fin de crear un diálogo más intenso entre las organizaciones de trabajadores y de patrones, así como para impulsar la creatividad y la productividad en los centros de trabajo. ${ }^{38}$

En este sentido, cada parte se comprometió a promover la observancia de su legislación laboral y a aplicarla efectivamente a través de medidas gubernamentales adecuadas, tales como proveer y alentar el uso de servicios de mediación, conciliación y arbitraje. ${ }^{39}$

Una de las funciones del Consejo de la Comisión para la Cooperación Laboral, que es el órgano rector de dicha Comisión, es facilitar las consultas de parte a parte, incluyendo el intercambio de información. Deberán procurar en todo momento lograr el consenso sobre la interpretación y aplicación del ACLAN, y harán su mayor esfuerzo por resolver, mediante cooperación y consultas, cualquier asunto que pudiera afectar su funcionamiento. ${ }^{40}$

Dentro de la parte de solución de controversias (quinta parte) se establece que cualquiera de las partes podrá solicitar por escrito consultas con cualquiera otra respecto a la existencia de una pauta persistente de omisiones. Si las partes no logran resolver el asunto por medio de consultas, cualquiera de las partes podrá solicitar por escrito una sesión extraordinaria del Consejo, que podrá recurrir a los buenos oficios, la con-

36 Artículo 24.

37 Artículos 31-34.

38 Firmado en las ciudades de México, Ottawa y Washington, D. C., el 14 de septiembre de 1993. Colección de tratados celebrados por México, México, Senado-SRE, t. XXXVII, 1992, pp. 1927 y 1979.

39 Artículo 3 (1) f.

40 Artículos 10 (1) f, 11 (1) i, y 20. 
ciliación, la mediación o a otros procedimientos de solución de controversias. Esto con el claro objetivo de evitar cualquier tipo de litigio. ${ }^{41}$

Se busca evitar lo más posible, por medio de acuerdos, diálogos, negociaciones y consultas, confrontaciones innecesarias, conflictos cuya solución es más factible fuera del litigio.

El TLCAN también apoya la solución de controversias privadas internacionales sobre asuntos de inversión y comercio a través del Comité Consultivo de Controversias Comerciales Privadas que establece el artículo 2022.42 El Comité ha señalado que la inclusión de disposiciones apropiadas en contratos comerciales internacionales que aborden la solución de controversias comerciales privadas es deseable. El Comité ha señalado que una cláusula sobre mecanismos alternativos para la solución de controversias bien redactada puede significar no solamente una resolución efectiva de cualquier controversia, adicionalmente puede disminuir violaciones al contrato al proveer un mecanismo efectivo para ejercer los derechos contractuales.

\section{Ley Modelo de Conciliación Comercial Internacional de las Naciones Unidas}

La Ley Modelo en Conciliación Comercial Internacional de las Naciones Unidas ${ }^{43}$ se inspira en la creencia de que los protagonistas de conflictos legales internacionales pueden resolverlos por sí mismos, sin la necesidad de tribunales o arbitrajes internacionales.

41 Artículos 27-29.

42 http://www.nafta-sec-alena.org/DefaultSite/index_s.aspx? DetailID=894.

43 Texto en www.uncitral.org. La Comisión sobre el Derecho Mercantil Internacional (CUNDMI) ha aprobado las siguientes leyes modelo: Ley Modelo sobre Arbitraje Comercial Internacional (1985), Ley Modelo sobre Transferencias Internacionales de Crédito (1992), Ley Modelo sobre Contratación Pública de Bienes, Obras y Servicios (1994), Ley Modelo sobre Comercio Electrónico (1996), Ley Modelo sobre la Insolvencia Transfronteriza (1997), Ley Modelo sobre las Firmas Electrónicas (2001) y Ley Modelo sobre Conciliación Comercial Internacional (2002). En 2005 adoptó la Convención de las Naciones Unidas sobre la Utilización de las Comunicaciones Electrónicas en los Contratos Internacionales. Véase el estupendo manual, Arbitraje y solución de controversias. Cómo solucionar las controversias mercantiles internacionales, México, Themis, Centro de Comercio Internacional UNCTAD-OMC, 2003. 
En la Comisión de las Naciones Unidas para el derecho mercantil internacional (CNUDMI) ${ }^{44}$ se negoció la Ley Modelo entre 2000 y 2002.45 Los resultados de dichas negociaciones fueron el Texto de la Ley Modelo y una Guía explicativa de su texto y sus antecedentes. ${ }^{46}$ La Ley Modelo consta de 14 artículos y busca propiciar una mayor integridad y certeza al proceso conciliatorio.

La guía se elaboró pensando en los órganos del Poder Ejecutivo y del Poder Legislativo que se hayan de encargar de efectuar la revisión legislativa en los países interesados. También la información de la guía fue concebida pensando en otros usuarios del texto como empresarios, jueces, abogados en ejercicio y círculos académicos. ${ }^{47}$

Posteriormente, la Asamblea General aprobó la Resolución en la que recomendó a todos los Estados que consideraran debidamente la posibili-

44 A partir del 25 de junio de 2007, y los años en que expiran sus respectivos mandatos son miembros de la CNUDMI los siguientes: Argelia (2010), Federación Rusa (2013), Mongolia (2010), Alemania (2013), Fidji (2010), Namibia (2013), Armenia (2013), Francia (2013), Nigeria (2010), Australia (2010), Gabón (2010), Noruega (2013), Austria (2010), Grecia (2013), Pakistán (2010), Bahrein (2013), Guatemala (2010), Paraguay (2010), Belarus (2010), Honduras (2013), Polonia (2010), Benin (2013), India (2010), Reino Unido de Gran Bretaña e Irlanda del Norte (2013), Bolivia (2013), Irán (República Islámica de) (2010), República Checa (2010), Bulgaria (2013), Israel (2010), República de Corea (2013), Camerún (2013), Italia (2010), Senegal (2013), Canadá (2013), Japón (2013), Serbia (2010), Chile (2013), Kenia (2010), Singapur (2013), China (2013), Letonia (2013), Sri Lanka (2013), Colombia (2010), Líbano (2010), Sudáfrica (2013), Ecuador (2010), Madagascar (2010), Suiza (2010), Egipto (2013), Malasia (2013), Tailandia (2010), El Salvador (2013), Malta (2013), Uganda (2010), España (2010), Marruecos (2013), Venezuela (República Bolivariana de) (2010), Estados Unidos (2010), México (2013) y Zimbabwe (2010).

45 En su 32o. periodo de sesiones, celebrado en 1999, la Comisión tuvo a su disposición la nota titulada Posible labor futura en materia de arbitraje comercial internacional (A/CN.9/460). La Comisión encomendó la labor a uno de sus grupos de trabajo, al que denominó Grupo de Trabajo II (Arbitraje y Conciliación) y decidió que entre los temas prioritarios figurase la labor sobre la conciliación. La ley modelo fue elaborada en el transcurso de cuatro periodos de sesiones del Grupo de Trabajo (32o. a 35o., los informes correspondientes figuran en los documentos A/CN.9/468, A/CN.9/485, A/CN.9/487 y A/CN.9/506).

46 A/CN.9/514.

47 Durante la preparación de la ley modelo participaron en el debate representantes de unos 90 Estados, 12 organizaciones intergubernamentales y 22 organizaciones internacionales no gubernamentales. Participó una representación del Comité 2022 del NAFTA sobre solución de controversias privadas comerciales internacionales, que incluía un jurista de cada uno de los tres países, Canadá, Estados Unidos y México. 
dad de incorporar a su derecho interno la Ley Modelo, en atención a la conveniencia de uniformar el derecho relativo a los procedimientos de solución de controversias y las necesidades concretas de la práctica comercial internacional en materia de conciliación..$^{48}$

El término "conciliación" se utiliza en la Ley Modelo para designar, en sentido amplio, todo procedimiento por el que una persona o un grupo de personas prestan asistencia a las partes en una controversia para que puedan llegar a una solución amistosa. En la conciliación, el conciliador ayuda a negociar una transacción en que se compaginen las necesidades y los intereses de las partes en la controversia. El tercero neutral no tiene autoridad para imponer a las partes una solución de la controversia.

En muy importante destacar que leyes nacionales y tratados internacionales usan diversos términos como conciliación, mediación, amigable composición, evaluación neutral, grupo de amigos, dictamen neutral, miniproceso o expresiones similares pare significar todo procedimiento por el que las partes en una controversia reciben ayuda de un tercero para solucionarla. Todos esos términos representan diversas técnicas y adaptaciones de procedimientos para dirimir controversias que son denominados métodos alternos a los tradicionales de solución de controversias por vía judicial.

En la Ley Modelo se utiliza el término "conciliación" para englobar a todos esos procedimientos. En la doctrina se hacen distinciones entre esos conceptos en función del método empleado por el tercero o del grado en que el tercero interviene en el proceso. En algunos casos, las diversas expresiones parecen más variantes lingüísticas que rasgos singulares del método empleado. En la medida en que uno "los mecanismos alternativos de solución de controversias" tenga como característica que el tercero se limita a ayudar a las partes a dirimir la controversia y de que no puede imponerles una decisión vinculante, dicha vía está comprendida en la Ley Modelo.

Dado que el conciliador no toma decisiones, no se necesitan garantías procesales, como las que existen en el los procesos judiciales o en el

48 Para los testimonios de la preparación de la Ley Modelo véase www.uncitral.org bajo el título Travaux préparatoires y en el Anuario de la CNUDMI. Esta información aparece en los seis idiomas oficiales de las Naciones Unidas (árabe, chino, español, francés, inglés y ruso). 
arbitraje. La ley considera crucial la flexibilidad de adaptar el proceso a las circunstancias de cada caso y a los deseos de las partes.

A los ojos de los negociadores de la ley, cuya inmensa mayoría fue de abogados, una preocupación central de la conciliación era tener la certeza de que lo que se hubiera declarado o admitido durante el procedimiento no se utilizaría como prueba en su contra en otro procedimiento. Se consideró que con una solución contractual no se podía lograr ese objetivo, por lo que varios de los artículos de la ley desarrollaron reglas, generalmente sujetas a la voluntad de las partes, en cuestiones como el papel del conciliador en actuaciones judiciales o arbitrales subsiguientes, el proceso de nombramiento de conciliadores, los principios amplios aplicables al procedimiento conciliatorio, confidencialidad de la información y la ejecutoriedad del acuerdo de transacción.

Canadá (2005), Croacia (2003), Hungría (2002) y Nicaragua (2005) han promulgado legislación basada en la Ley Modelo de la CNUDMI sobre Conciliación Comercial Internacional. Se han preparado leyes uniformes influidas por la Ley Modelo y sus principios básicos en: los Estados Unidos de América (Ley Uniforme de Mediación, aprobada en 2001 por la Conferencia Nacional de Comisarios sobre Derecho Estatal Uniforme) y promulgada por los estados de Illinois, Iowa, Nebraska, Nueva Jersey, Ohio y Washington. ${ }^{49}$

La Ley Modelo debería ser debatida en el Poder Legislativo a efecto de incorporarla a la legislación mexicana como una de las leyes sobre mecanismos alternativos de solución de controversias a que hace referencia el artículo 17 de la Constitución. ${ }^{50}$

49 Véase www.nccusl.org/Update/. En este sitio aparece el texto del Acta Uniforme de Mediación (Uniform Mediation Act) adoptada en 2001 y modificada en 2003 para incorporar la referencia a la ley modelo. Sobre la incorporación de la ley modelo al Uniform Mediation Act en los Estados Unidos, Díaz, Luis Miguel y Oretskin, Nancy, "The US Uniform Mediation Act and the Draft UNCITRAL Model Law on International Commercial Conciliation", Practising Law Institute, Nueva York, marzo de 2002, pp. 791-803, y en http://www.mediate.com//articles/daiz2.cfm.

50 En un periodo breve el Poder Legislativo debería incorporar a la legislación mexicana la Ley Modelo de Conciliación Comercial Internacional de 2002, como lo hizo con la Ley Modelo de Arbitraje Comercial de 1985 en 1993. Una propuesta para estos efectos elaborada por José Luis Siqueiros y el autor en Díaz, Luis Miguel, "El desaprender el pensamiento jurídico como acceso a la Ley Modelo de Conciliación Comercial Internacional", Anuario Mexicano de Derecho Internacional, vol. VI, 2006, pp. 167-198, http://www.juridicas.unam.mx/publica/rev/derint/cont/6/art/art4.htm. 


\section{Directiva de la Unión Europea sobre la mediación}

El Parlamento Europeo y el Consejo de la Unión Europea adoptaron la Directiva sobre ciertos aspectos de la mediación en asuntos civiles y mercantiles que entró en vigor el 13 de junio de 2008 y que se compone de 14 artículos. $^{51}$

En la Directiva se pidió a los Estados miembros que instauraran procedimientos alternativos de carácter extrajudicial. Se acordó que el objetivo de asegurar un mejor acceso a la justicia, como parte de la política de la Unión Europea, debe abarcar el acceso a métodos tanto judiciales como extrajudiciales de resolución de litigios. La Directiva debe contribuir a la disponibilidad de servicios de mediación.

Se asumió como más probable que los acuerdos resultantes de la mediación se cumplan voluntariamente y también que preserven una relación amistosa y viable entre las partes.

Se estimó que la mediación no debe considerarse como una alternativa peor que el proceso judicial, por lo que los Estados miembros deben asegurar que las partes en un acuerdo escrito resultante de la mediación puedan hacer que su contenido tenga fuerza ejecutiva.

Con el fin de alentar a las partes a hacer uso de la mediación, los Estados miembros deben garantizar que sus normas sobre plazos de caducidad y prescripción no impidan a las partes recurrir a los tribunales o al arbitraje en caso de que fracase su intento de mediación. También se garantiza la confidencialidad de la mediación.

Los Estados miembros deben alentar a que se informe al público en general de la forma de entablar contacto con mediadores y organizaciones que presten servicios de mediación. También deben alentar a los profesionales del derecho a informar a sus clientes de las posibilidades que ofrece la mediación.

Los Estados miembros fomentarán la elaboración de códigos de conducta voluntarios y la adhesión de los mediadores y las organizaciones que presten servicios de mediación a dichos códigos, así como otros mecanismos efectivos de control de calidad referentes a la prestación de servicios de mediación y fomentarán la formación inicial y continua de me-

51 Texto en 24.5.2008 ES Diario Oficial de la Unión Europea L 136/3. Texto en Internet en http://eur-lex.europa.eu/LexUriServ/LexUriServ.do?uri=OJ:L:2008:136:00 03:0008:ES:PDF. 
diadores para garantizar que la mediación se lleve a cabo de forma eficaz, imparcial y competente en relación con las partes.

Los Estados miembros pondrán en vigor las disposiciones legales, reglamentarias y administrativas necesarias para dar cumplimiento a la presente Directiva antes del 21 de mayo de 2011.52

\section{DERECHO MEXICANO SOBRE LOS MECANISMOS ALTERNATIVOS DE SOLUCIÓN DE CONTROVERSIAS}

\section{Relación de leyes con referencias a mecanismos alternativos}

Dice el dicho popular que nada es nuevo bajo el sol. Pues bien, aun antes de la entrada en vigor del nuevo artículo 17 ya existían numerosos preceptos legales sobre los mecanismos alternativos de solución de controversias, esparcidos en leyes mexicanas con ámbitos muy variados.

Las leyes que se refieren a estos mecanismos alternativos utilizan diversos vocablos para referirse a ellos, que incluyen: conciliación, mediación, procedimiento de conciliación, conciliación de intereses, amigable composición, conciliación entre o de las partes, propuestas de conciliación, diálogo, grupo de amigos, negociaciones, concertación, avenimiento, procedimiento conciliatorio, instancia conciliatoria, composición amistosa.

Entre las Leyes que utilizan referencias a los mecanismos alternativos de solución de controversias destacan: ${ }^{53}$ Código Financiero del Distrito Federal, ${ }^{54}$ Ley Agraria, ${ }^{55}$ Ley de Instituciones de Crédito, ${ }^{56}$ Código de Procedimientos Civiles para el Distrito Federal, ${ }^{57}$ Código Federal de Procedimientos Penales, ${ }^{58}$ Ley de Asistencia y Prevención de la Violen-

52 Artículo 12, Incorporación al ordenamiento jurídico de los Estados miembros.

53 Textos de las leyes en http://www.diputados.gob.mx/LeyesBiblio/index.htm.

54 Diario Oficial de la Federación, 31 de diciembre de 1994, en vigor a partir del 1o. de enero de 1995.

55 Diario Oficial de la Federación, 26 de febrero de 1992, en vigor a partir del 27 de febrero de 1992.

56 Diario Oficial de la Federación, 18 de julio de 1990, en vigor a partir del 19 de julio de 1990.

57 Diario Oficial de la Federación (por partes), 11 a 21 de septiembre de 1932, en vigor a partir del 1o. de octubre de 1932.

58 Diario Oficial de la Federación, 30 de agosto de 1934, en vigor a partir del 11 de octubre de 1934. 
cia Familiar, ${ }^{59}$ Ley de la Comisión de Derechos Humanos del Distrito Federal, ${ }^{60}$ Ley de la Comisión Nacional de Derechos Humanos, ${ }^{61}$ Ley del Infonavit, ${ }^{62}$ Ley del Seguro Social, ${ }^{63}$ Ley Federal de Protección al Consumidor, ${ }^{64}$ Ley Federal de Turismo, ${ }^{65}$ Ley Federal de Derecho de Aut tor, ${ }^{66}$ Ley General de Sociedades Cooperativas, ${ }^{67}$ Ley General del Equilibrio Ecológico y Protección al Ambiente, ${ }^{68}$ Ley Orgánica de la Administración Pública del Distrito Federal, ${ }^{69}$ Ley Orgánica de la Procuraduría General de Justicia del Distrito Federal, ${ }^{70}$ Ley Orgánica de la Procuraduría General de la República, ${ }^{71}$ Ley Orgánica del Tribunal Superior de Justicia del Distrito Federal, ${ }^{72}$ Ley para el Diálogo, la Conciliación y la Paz Digna en Chiapas, ${ }^{73}$ Ley para el Tratamiento de Menores Infractores para el Distrito Federal en Materia Común y para toda la República en

59 Gaceta Oficial del Distrito Federal, 8 de julio de 1996 y en el Diario Oficial de la Federación el 9 de julio de 1996, en vigor desde el 7 de agosto de 1996.

60 Diario Oficial de la Federación, 22 de junio de 1993, en vigor a partir del 23 de junio de 1993.

61 Diario Oficial de la Federación, 29 de junio de 1992, en vigor a partir del 30 de junio de 1992.

62 Diario Oficial de la Federación, 24 de abril de 1972, en vigor el mismo día 24 de abril de 1972.

63 Diario Oficial de la Federación, 21 de diciembre de 1995, en vigor a partir del 11 de julio de 1997.

64 Diario Oficial de la Federación, 24 de diciembre de 1992, en vigor a partir del 25 de diciembre de 1992.

65 Diario Oficial de la Federación, 31 de diciembre de 1992, en vigor a los treinta días de su publicación.

66 Diario Oficial de la Federación, 24 de diciembre de 1996, en vigor a partir del 24 de marzo de 1997.

67 Diario Oficial de la Federación, 3 de agosto de 1994, en vigor a los treinta días siguientes al de su publicación.

68 Diario Oficial de la Federación, 28 de enero de 1988, en vigor el día 1o. de marzo de 1998.

69 Gaceta Oficial del Distrito Federal, 31 de diciembre de 1994, en el Diario Oficial de la Federación el 30 de diciembre de 1994, en vigor desde el 11 de enero de 1995.

70 Diario Oficial de la Federación, 30 de abril de 1996, en vigor a partir del 1 de mayo de 1996.

71 Diario Oficial de la Federación, 10 de mayo de 1996, en vigor a partir del 11 de mayo de 1996.

72 Gaceta Oficial del Distrito Federal, 29 de enero de 1996, y Diario Oficial de la Federación, 7 de febrero 1996, en vigor desde el 28 de febrero de 1996.

73 Diario Oficial de la Federación, 11 de marzo de 1995, en vigor a partir del mismo 11 de marzo de 1995. 
Materia Federal, ${ }^{74}$ Ley General de Instituciones y Sociedades Mutualistas de Seguros ${ }^{75}$ Ley Federal de Instituciones de Fianzas, ${ }^{76}$ Ley del Mercado de Valores, ${ }^{77}$ Ley Federal del Trabajo, ${ }^{78}$ Ley Federal de los Trabajadores al Servicio del Estado Reglamentaria del Apartado B del Artículo 123 Constitucional, ${ }^{79}$ Ley de la Procuraduría Social del Distrito Federal ${ }^{80}$ Comisión Nacional de Arbitraje Médico,${ }^{81}$ Ley de Obras Publicas y Servicios relacionados con las mismas, ${ }^{82}$ Ley de Protección y Defensa al Usuario de Servicios Financieros, ${ }^{83}$ Ley de Concursos Mercantiles,${ }^{84}$ Ley Federal para Prevenir y Eliminar la Discriminación, ${ }^{85}$ Ley del Notariado para el Distrito Federal. ${ }^{86}$

Desde otra perspectiva, recientemente ha tenido lugar un desarrollo sin precedentes de la mediación como medio alterno en el Poder Judicial. El Libro blanco reconoce: "Los medios alternativos para resolver controversias han experimentado un rápido desarrollo en los poderes judiciales del país. Más de la mitad de ellos cuentan ya con áreas que ofrecen servicios alternativos de justicia". ${ }^{87}$

74 Diario Oficial de la Federación, 24 de diciembre de 1991, en vigor a los sesenta días siguientes a su publicación.

75 Diario Oficial de la Federación, 31 de agosto de 1935, en vigor desde el 31 de agosto de 1935.

76 Diario Oficial de la Federación, 29 de diciembre de 1950, en vigor desde el 13 de enero de 1951.

77 Diario Oficial de la Federación, 2 de enero de 1975, en vigor a partir del 3 de enero de 1975.

78 Diario Oficial de la Federación, 1o. de abril de 1970, en vigor a partir del 11 de mayo de 1970, con excepción de los artículos 71 y 87 que entraron en vigor el 11 de julio de 1970, y el artículo 80 que entró en vigor el 11 de septiembre de 1970.

79 Diario Oficial de la Federación, 28 de diciembre de 1963, en vigor a partir del 29 de diciembre de 1963.

80 Gaceta Oficial del Distrito Federal, 28 de septiembre de 1988, en vigor a partir del 29 de septiembre de 1988.

81 Diario Oficial de la Federación, 31 de mayo 1996.

82 Diario Oficial de la Federación, 4 de enero de 2000. Última reforma publicada DOF 07-07-2005.

83 Diario Oficial de la Federación, 18 de enero de 1999. Última reforma publicada DOF 07-07-2005.

84 Diario Oficial de la Federación, 12 de mayo de 2000.

85 Diario Oficial de la Federación, 11 de junio de 2003.

86 Gaceta Oficial del Distrito Federal, 28 de marzo de 2000.

87 http://www.scjn.gob.mx/PortalSCJN/RecJur/ReformaJudicial/LibroBlancoReform aJudicial/. 
Se han impulsado reformas legales procesales y establecido centros de mediación en los poderes judiciales de Aguascalientes, Baja California Sur, Chihuahua, Coahuila, Colima, Distrito Federal, Guanajuato, Jalisco, Michoacán, Nayarit, Nuevo León, Oaxaca, Puebla, Querétaro, Quintana Roo, Sonora, Tabasco, Tamaulipas. ${ }^{88}$

El Centro de Justicia Alternativa del Tribunal Superior de Justicia del Distrito Federal (CJA), creado en 2003, ofrece servicios de mediación familiar, civil o comercial y penal. ${ }^{89} \mathrm{Su}$ efecto en la población ha sido bien recibido pues ya existan cientos de testimonios personales de individuos agradecidos al CJA por haber facilitado soluciones negociadas a sus conflictos y por el cambio que operó en sus personas y relaciones personales..$^{90}$

En la vertiente privada, negociadores, mediadores, abogados y empresarios han creado varios Centros Privados de Mediación. Como ejemplos: la Cámara de Comercio y Servicios de Turismo de la Ciudad de México ${ }^{91}$ el Instituto de Mediación México, ${ }^{92}$ el Instituto Mexicano de Mediación, ${ }^{93}$ el Centro Mexicano de Mediación, ${ }^{94}$ el Centro de Mediación Notarial $^{95}$ y el Centro Interdisciplinario para el Manejo de Conflictos. ${ }^{96}$ En 2007 se constituyó la Asociación para la Resolución de Conflictos, A. C. en la Ciudad de México (ARCO). ${ }^{97}$ Se han celebrado siete Congresos Nacionales de Mediación entre 2001 y 2007. ${ }^{98}$ En enero de 2008 entró en vigor la Ley de Justicia Alternativa del Estado de Jalisco ${ }^{99}$ y la Ley de

88 www.mediacionenmexico.org.

89 Díaz, Luis Miguel, "La mediación en el Centro de Justicia Alternativa del Tribunal Superior de Justicia del Distrito Federal: ¿revolución o aberración?”, Foro, Barra de Abogados, XIII época, t. XVI, núm 2, segundo semestre, 2003, pp. 93-101. http://www. bma.org.mx/. También de Díaz, Luis Miguel, Centro de justicia alternativa de la ciudad de México: testimonios de un curso alternativo sobre mediación; http://www.mediate. $\mathrm{com} / 2008$.

90 http://www.tsjdf.gob.mx/justiciaalternativa/index.html.

91 http://www.ccmexico.com.mx/\}.

92 http://www.congresodemediacion.org/sp/index.php.

93 http://www.imm.org.mx/listado.htm.

94 http://www.centromexmediacion.com/.

95 http://www.vivirenpaz.org. $m x / p g /$ convocatorias.html.

96 http://www.solucionegociada.com.

97 http://www.arco.org. $m x /$.

98 http://www.congresodemediacion.org/sp/index.php.

99 Periódico Oficial El Estado de Jalisco, 30 de enero, 2007. http://www.ordenjuri dico.gob.mx/Estatal/JALISCO/Leyes/JALEY029.pdf. 
Justicia Alternativa del Tribunal Superior de Justicia del Distrito Federal. ${ }^{100}$

\section{Ley sobre la Celebración de Tratados}

Desde 1992 es vigente La Ley sobre la Celebración de Tratados (LSCT). ${ }^{101}$ Ésta fue y es una ley polémica y discutida que se anticipó a la Reforma de 2008 y que adquiere notoria relevancia a la luz del nuevo artículo 17 que señala que las leyes preverán mecanismos alternativos de solución de controversias. ${ }^{102}$

La LSCT regula la celebración de tratados y los mecanismos alternativos internacionales de solución de controversias. El artículo 1o. de la LSCT indica que su objeto es regular la celebración de tratados y acuerdos interinstitucionales en el ámbito internacional; el artículo 2o. señala definiciones; el artículo 3o. se refiere a los plenos poderes que debe otorgar el presidente de la República; el artículo 4o. trata del trámite de los tratados en el Senado; el artículo 5o. de cómo se obliga México en un tratado; el artículo 6o. establece que la Secretaría de Relaciones Exteriores coordinará las acciones para celebrar tratados; el artículo 7o. estable-

100 Gaceta Oficial del Distrito Federal, 8 de enero, 2008. http://www.tsjdf.gob.mx/jus ticiaalternativa/ley_just_alt_tsjdf.pdf.

101 Un antecedente de propuesta a la conveniencia de actualizar la legislación en relación a la celebración de tratados en México, en Díaz, Luis Miguel, "Tratados internacionales y la Constitución", Anuario Jurídico, X, 1983, pp. 533-575.

102 Diario Oficial de la Federación del 2 de enero, 1992. Véase Ley de Tratados, libro editado por la Secretaría de Relaciones Exteriores que contiene la exposición de motivos y texto de iniciativa al Senado; y dictámenes de ambas cámaras del Poder Legislativo Federal con las versiones estenográficas, 1992, pp. 59-60. Sobre teoría y práctica de tratados en México: Díaz, Luis Miguel, "National Treaty Law and Practice: Mexico", en varios autores, National Treaty Law and Practice, Edited by Duncan B. Hollis, Merritt Blakeslee \& Benjamin Ederington, Leiden-Boston, Martinus Nijhoff Publishers, ASIL, 2005, pp. 437-482, http://www.brill.nl/default.aspx? partid=210\&pid=21990. Sobre la Ley de Tratados: Palacios Treviño, Jorge, Análisis crítico jurídico de la Ley sobre la Celebración de Tratados, México, Secretaría de Relaciones Exteriores, 2000; reseña del libro de Jorge Palacios Treviño hecha por José Humberto Castro, Anuario Mexicano de Derecho Internacional, vol. II, 2002; Pelayo, Candelaria, Tratados internacionales, http://www.monografias.com/trabajos 15/tratados-internacionales/tratados-internacional es.shtml; Díaz, Luis Miguel, "Ley sobre la celebración de tratados", en Valdez, Rubén y Romero, José Elías (coord.), La modernización del derecho mexicano, México, Porrúa, 1994, pp. 770-779. 
ce la obligación de mantener informada a la Secretaría de Relaciones Exteriores sobre acuerdos interinstitucionales; y del artículo 8o. al 11 se establecen reglas sobre mecanismos alternativos internacionales para solución de controversias legales.

En la década de los noventa, en apariencia, no era necesaria una ley de tratados porque México ya había incorporado a su legislación, de conformidad con el artículo 133 de la Constitución, ${ }^{103}$ a la Convención de Viena sobre el Derecho de los Tratados de 1969, ratificada en 1974 y a la Convención de Viena sobre el Derecho de los Tratados entre Estados y Organizaciones Internacionales o entre Organizaciones Internacionales de 1986, ratificada en 1988. ${ }^{104}$

Sin embargo, existían dos motivaciones principales del legislador que iban más allá del contenido sustantivo de las Convenciones sobre Tratados de Viena. La primera era que no había sustento en ninguna ley para la práctica de celebrar acuerdos ejecutivos internacionales, que no eran tratados en el sentido del artículo 133 de la Constitución, y cuya elaboración era creciente y desordenada; y la segunda era proporcionar un fundamento en la ley sobre los mecanismos alternativos internacionales para la solución de controversias.

Respecto a los acuerdos ejecutivos, se estableció en la LSCT el concepto de los acuerdos interinstitucionales (acuerdos ejecutivos) que son acuerdos internacionales que no obligan a México como país sino sólo a las dependencias o entidades firmantes y respecto a sus ámbitos de competencia. Los acuerdos interinstitucionales son convenios regidos por el derecho internacional público, celebrado por escrito entre cual-

103 En relación a la jerarquía de los tratados en el orden jurídico mexicano, según el artículo 133 constitucional, véase Becerra Ramírez, Manuel, "Comentarios sobre la tesis P. IX/2007 y P. VIII/2007 de la Suprema Corte de Justicia de la Nación de 2007”, y Cossío Díaz, José Ramón, "Jerarquía, división competencial en relación con los tratados internacionales en derecho mexicano", Anuario Mexicano de Derecho Internacional, vol. VIII, 2008, pp. 861-882, http://www.juridicas.unam.mx/publica/rev/indice.htm? $r=$ derint $\& n=8$. Perezcano, Hugo, "Los tratados internacionales en el orden jurídico mexicano", Anuario Mexicano de Derecho Internacional, vol. VII, 2007, pp. 247-279, http://www.ju ridicas.unam.mx/publica/rev/derint/cont/7/art/art7.htm.

104 La de 1969 en http://www.oas.org/XXXVGA/espanol/doc_referencia/Convencion Viena.pd. La de 1986 en http://untreaty.un.org/ilc/texts/instruments/english/conventions /1 2 1986.pdf. Existe además la Convención de Viena sobre sucesión de Estado en materia de tratados de 1978, que México no ha firmado ni ratificado. En http://untreaty.un. org/ilc/texts/instruments/english/conventions/3_2_1978.pdf. 
quier dependencia u organismo descentralizado de la administración pública federal, estatal o municipal y uno o varios órganos gubernamentales extranjeros $\mathrm{u}$ organizaciones internacionales, cualquiera que sea su denominación, sea que derive o no de un tratado previamente aprobado. El ámbito material de los acuerdos interinstitucionales deberá circunscribirse exclusivamente a las atribuciones propias de las dependencias y organismos descentralizados de los niveles de gobierno mencionados que los suscriben.

Por lo anterior parece simplificado y exagerado entender a la LSCT como contraria a la Constitución por establecer la base jurídica de los acuerdos interinstitucionales (denominados históricamente como acuerdos ejecutivos) que no requieren aprobación del Senado. Por una parte, la práctica internacional de los países muestra que a la luz del derecho internacional existe una gran variedad de acuerdos con efectos jurídicos, que no son tratados de conformidad a las Convenciones de Viena. Por lo que respecta al artículo 133 de la Constitución, el mismo texto de la LSCT reitera lo que son los tratados de conformidad con la Constitución y define a los acuerdos interinstitucionales como convenios diferentes a los tratados. La historia legislativa muestra la claridad de los legisladores al distinguir los tratados de los acuerdos interinstitucionales. En el proceso legislativo creador de la LSCT, el senador Porfirio Muñoz Ledo señaló:

Tratándose de acuerdos interinstitucionales suscritos por el Gobierno de un Estado de la Federación, es obvio que no compromete al Gobierno de los Estados Unidos Mexicanos, que es el Gobierno Federal. Esto es claro. Tratándose de acuerdos interinstitucionales firmados por un municipio, ayuntamiento, es obvio que no compromete al Gobierno de la Federación. Esto es obvio. Tratándose de acuerdos suscritos por un organismo descentralizado, también es obvio que no comprometen al Gobierno mismo, por la naturaleza específica de un organismo descentralizado. La confusión se establece cuando ese acuerdo es firmado por una dependencia del Ejecutivo. Entonces me permitiría que quedara esta afirmación muy clara en el Diario de los Debates: Los acuerdos llamados interinstitucionales, firmados o suscritos con autorización de la Secretaría de relaciones exteriores por una dependencia centralizada del Poder Ejecutivo de la Unión, sólo 
comprometen a esa dependencia en la esfera administrativa, y no comprometen de modo alguno al Gobierno de los estados Unidos Mexicanos. ${ }^{105}$

Según el artículo 2o., párrafo 1, inciso $a$, de la Convención de Viena de 1969: Se entiende por "tratado" un acuerdo internacional celebrado por escrito entre Estados y regido por el derecho internacional, ya conste en un instrumento único o en dos o más instrumentos conexos y cualquiera que sea su denominación. Así, los acuerdos interinstitucionales no son tratados en el sentido de la Convención porque no son firmados por un Estado como centro de imputación de derechos y deberes a la luz del derecho internacional. La Convención se aplica únicamente a tratados celebrados entre Estados, por escrito y que sean regidos por el derecho internacional.

Consecuentemente, parece no haber fundamento para argumentar que la LSCT modifica el texto del artículo 133 que exige la aprobación del Senado de los Tratados. A partir de la LSCT la Secretaría de Relaciones Exteriores ha establecido criterios para determinar si un asunto es materia de un tratado o de un acuerdo interinstitucional. ${ }^{106}$

La segunda y principal motivación del legislador que creó la LSCT fue la de proporcionar una base legal clara e inequívoca de los mecanismos alternativos internacionales de solución de controversias que serían inevitables en los tratados de libre comercio e inversión que se negociarían a partir de la década de los noventa. ${ }^{107} \mathrm{El}$ legislador previó el futuro, se anticipó a las circunstancias, observó y reconoció la tendencia mundial en la materia y ofreció una respuesta jurídica y no política para dichos mecanismos alternativos. Además, previó el argumento de violación al artículo 27 de la Constitución que consagra la Cláusula Calvo. ${ }^{108}$

105 Ley de Tratados, cit., nota 102, pp. 59-60.

106 Véase Guía para la conclusión de tratados y acuerdos según la Ley sobre la Celebración de Tratados, México, Secretaría de Relaciones Exteriores, 1999; Palacios Treviño, Jorge, Tratados: legislación y práctica en México, México, Universidad Iberoamericana, 2007.

107 Véase infra sección Los mecanismos alternativos de solución de controversias públicas y privadas internacionales en el Tratado de Libre Comercio de América del Norte.

108 Para evitar abusos en el otorgamiento de la protección diplomática algunos países de Latinoamérica, como México en el artículo 27 de la Constitución, obligan a insertar la Cláusula Calvo en los contratos que celebren con extranjeros domiciliados en su territorio. Por esta cláusula, la parte extranjera renuncia a solicitar la protección diplomática de 
El legislador en el Dictamen de la Cámara de Diputados estableció con precisión una hermenéutica jurídica: "Debe destacarse que el principio conocido como Cláusula Calvo, no se altera con la presente Ley, en la inteligencia de que, al someterse a un mecanismo internacional de solución de controversias, en modo alguno podría pensarse que se está invocando la protección de un gobierno extranjero". ${ }^{109}$

El artículo 8o. de la LSCT establece, define y limita a los mecanismos alternativos internacionales de solución de controversias convenidos en Tratados:

Cualquier tratado o acuerdo interinstitucional que contenga mecanismos internacionales para la solución de controversias legales en que sean parte, por un lado la Federación, o personas físicas o morales mexicanas y, por el otro, gobiernos, personas físicas o morales extranjeras u organizaciones internacionales, deberá:

I. Otorgar a los mexicanos y extranjeros que sean parte en la controversia el mismo trato conforme al principio de reciprocidad internacional;

II. Asegurar a las partes la garantía de audiencia y el debido ejercicio de sus defensas; $y$

III. Garantizar que la composición de los órganos de decisión asegure su imparcialidad.

Fue entonces que con fundamento en el artículo 8o. de la LSCT, México negoció internacionalmente e incorporó a su legislación nacional, mediante la aprobación del Senado, los mecanismos alternativos de solución de controversias públicas y privadas internacionales contenidos en el Tratado de Libre Comercio de América del Norte con Canadá y Estados Unidos; y en los Acuerdos para la Promoción y Protección Reciproca de las Inversiones (APPRI) que contienen mecanismos alternativos de solución de controversias en materia de inversión celebrados con Alemania, Australia, Austria, Corea, Cuba, Dinamarca, España, Eslovaquia,

su gobierno en caso de surgir dificultades del contrato, y se compromete a someter todas las reclamaciones a las leyes, autoridades y tribunales del país con el cual está contratando (http://www.monografias.com/trabajos11/clausu/clausu.shtml\#intro). En años recientes los países del continente cambiaron sus interpretaciones políticas de la Cláusula Calvo a efecto de acordar mecanismos alternativos internacionales en relación a inversiones extranjeras; pero sólo México creó una Ley (la de Tratados) para dar base legal a dichos mecanismos.

109 Ley de Tratados, cit., nota 102, p. 75 
Finlandia, Francia, Grecia, India, Islandia, Italia, Países Bajos, Panamá, Portugal, Reino Unido, República Checa, Suecia, Suiza, Trinidad y Tobago, Unión Belgo-Lux, Uruguay. ${ }^{110}$

El artículo 9o. de la LSCT fue pensado como una limitante al posible ámbito de los mecanismos alternativos de solución de controversias al excluir asuntos específicos. Por ello, señala que no se reconocerá cualquier resolución de los órganos de decisión de los mecanismos internacionales para la solución de controversias a que se refiere el artículo 8o. cuando esté de por medio la seguridad del Estado, el orden público o cualquier otro interés esencial de la nación.

El artículo 10 de la LSCT es una respuesta a una cuestión más de redundancia que de exigencia legal. La redundancia era ratificar la facultad constitucional del presidente de la República en política exterior, al indicar que nombraría a quienes participen como árbitros, comisionados o expertos en los órganos de decisión de los mecanismos internacionales de solución de controversias. Sin embargo, como lo indica el propio artículo, dichos nombramientos son de conformidad con los tratados aplicables a los mecanismos. En la práctica, son los funcionarios responsables en las dependencias involucradas en los mecanismos los que nombran de acuerdo con los tratados aplicables a quienes participen como árbitros, comisionados o expertos en los órganos de decisión de dichos mecanismos. ${ }^{111}$

El artículo 11 de la LSCT ofrece certeza jurídica sobre el valor jurídicamente vinculante de los mecanismos de solución de controversias, que ahora se sustentaría en el nuevo artículo 17 constitucional. Establece que las sentencias, laudos arbitrales y demás resoluciones jurisdiccionales derivados de la aplicación de los mecanismos internacionales para la solución de controversias legales tendrán eficacia y serán reconocidos en la República, y podrán utilizarse como prueba en los casos de nacionales que se encuentren en la misma situación jurídica, de conformidad con el Código Federal de Procedimientos Civiles y los tratados aplicables. ${ }^{112}$

110 http://www.economia.gob. $m x / ? P=1210$.

111 Vega, Gustavo et al., op. cit., nota 27.

112 En relación al reconocimiento de la validez legal de los mecanismos alternos a que hace referencia el artículo 11 de la Ley, se encuentran sobre todo dos tratados internacionales de los que México es parte: la Convención sobre el Reconocimiento y Ejecución de la Sentencias Arbitrales Extranjeras, conocida como la Convención de Nueva York de 1958, que establece los requisitos para la ejecución del laudos extranjeros, y la 


\section{Ley sobre Aprobación de Tratados Internacionales} en Materia Económica

En 2004 se aprobó la Ley sobre Aprobación de Tratados Internacionales en Materia Económica (LSATIME). ${ }^{113}$ La Ley contiene 14 artículos ordenados en cinco capítulos. El capítulo I trata sobre disposiciones generales; el capítulo II acerca de los objetivos de la celebración de tratados; el capítulo III trata de los procedimientos de información sobre la celebración de tratados; el IV sobre la participación de los poderes de las entidades federativas y de las organizaciones empresariales, ciudadanas y sindicales; y el capítulo V sobre el cálculo de plazos y términos, y la aplicación supletoria de la Ley de Comercio Exterior y la LSCT.

El objeto de la LSATIME es reglamentar el artículo 93 de la Constitución respecto a las facultades constitucionales del Senado de requerir información a los secretarios de Estado, jefes de departamento administrativo, así como a los directores de los organismos descentralizados competentes sobre la negociación, celebración y aprobación de tratados relacionados con el comercio de mercancías, servicios, inversiones, transferencia de tecnología, propiedad intelectual, doble tributación, cooperación económica y con las demás materias a que se refiere este ordenamiento cuando se relacionen con las anteriores.

La LSATIME no busca reglamentar el artículo 133 de la Constitución sino directamente el artículo 93 que se refiere al Senado e indirectamente busca poner controles al Poder Ejecutivo en el proceso de celebración de tratados. ${ }^{114}$

Convención Interamericana sobre Arbitraje Comercial Internacional, conocida como la Convención de Panamá de 1975, se aplica a los países de la región y viene a ser un complemento a la Convención de Nueva York. La Convención de 1958 es quizá el instrumento jurídico internacional más efectivo en toda la historia del derecho comercial internacional. Casi todos los países del planeta son parte. La eficacia del arbitraje internacional radica en que un laudo arbitral puede ser ejecutado contra la parte vencida. La mayoría de los laudos arbitrales se cumplen voluntariamente.

113 Diario Oficial de la Federación del 2 de septiembre, 2004. Comentario en Díaz, Luis Miguel, "Approving Treaties on Economic Matters", Inter-American Trade Report, vol. 12, núm. 1, enero de 2005, p. 5. Texto Ley en http://www.ordenjuridico.gob.mx/Fe deral/PL/CU/Leyes/02092004(2).pdf.

114 Opinión y análisis de la LSATIME de Becerra Ramírez, Manuel, "Ley sobre la Aprobación de Tratados Internacionales en Materia Económica", Anuario Mexicano de 
En respuesta al clima de mayor integración de los Poderes de la Unión en el manejo de los asuntos públicos la LSATIME impone la colaboración del Ejecutivo y Legislativo en la negociación y aprobación de tratados. Históricamente, el papel del Legislativo era casi simbólico, de mera aprobación de los tratados conforme al artículo 133. Para lograr una participación más efectiva, en vez de hacer una revisión de la Constitución o de la LSCT, el legislador tomó el camino de imponer la participación activa del propio legislativo, limitándolo a tratados en materia económica. ¿Extraño criterio?

Responde a un deseo democratizador el involucrar activamente a dos Poderes de la Unión en la celebración de tratados aunque no se comprende porque sólo a los tratados en materia económica. Destaca el objetivo general de "promover la transparencia en las relaciones comerciales internacionales", que implica el reconocimiento no sólo de las voluntades entre los Poderes sino también frente a la sociedad. El artículo 11 indica: "Sin distinción alguna los ciudadanos y las organizaciones empresariales, ciudadanas y sindicales podrán emitir su opinión ante el Senado de la República. Las comunicaciones entre ciudadanos, organizaciones y las comisiones correspondientes podrán ser orales en audiencia o por escrito. En todo caso, serán públicas, salvo disposición legal en contrario".

La LSATIME revalida la trascendencia de los mecanismos alternativos internacionales para la solución de controversias en el texto de su artículo 4o. que incorpora literalmente el artículo 8o. de la LSCT de 1992.

\section{EL FUTURO DE LOS MECANISMOS ALTERNATIVOS DE SOLUCIÓN DE CONTROVERSIAS}

El nuevo artículo 17 de la Constitución al establecer una base constitucional para los mecanismos alternativos de solución de controversia se inserta en una tendencia mundial de disminuir la participación del Estado en la vida de los particulares y de reconocer los recursos de los individuos para solucionar por sí mismos sus conflictos.

El uso de los mecanismos alternativos de solución de controversias es una opción para fortalecer el sistema de impartición de justicia en

Derecho Internacional, vol. V, 2005, pp. 697-699. http://www.juridicas.unam.mx/publi ca/rev/derint/cont/5/pim/pim31.htm. 
nuestro país. No se trata de acortar la responsabilidad del Poder Judicial sino de racionalizar el uso de sus recursos y al mismo tiempo de brindar al individuo y a la sociedad opciones para el manejo de sus conflictos. Esta tarea es retadora pues significa entrelazar dos sistemas interdependientes que tienen el mismo propósito.

Si bien el desarrollo de la justicia alternativa es todavía incipiente, las experiencias muestran el importante potencial de instituciones como la mediación que complementa el servicio que se da a través de la justicia ordinaria. Precisamente la posición complementaria de la justicia alternativa respecto de la justicia ordinaria, genera una estrecha relación entre ambos servicios; la primera puede funcionar siempre y cuando la segunda también funcione adecuadamente. ${ }^{115}$

Con el mandato constitucional como base, tanto el Poder Judicial como el Poder Legislativo deberán crear jurisprudencia y aprobar leyes que impulsen el uso de los mecanismos alternativos de solución de controversias. El Libro blanco indica:

Se enfatizó la importancia del reconocimiento de los laudos y convenios emitidos en los procesos que se desarrollan dentro del ámbito de la justicia alternativa. Esta circunstancia resulta especialmente relevante si se toma en consideración que los beneficios de la justicia alternativa pueden desaparecer si la justicia ordinaria no es eficiente en el reconocimiento oportuno de las decisiones arbitrales. Este es un espacio en donde el Poder Judicial Federal debe generar jurisprudencia que propicie el desarrollo de la justicia alternativa. ${ }^{116}$

En este momento, a la luz de los mecanismos alternativos, es insuficiente el abogado litigante con mente de guerrero que defiende y acusa, sino que aparece la necesidad de capacitar a los abogados como conciliadores y pacificadores. Se requiere educación para una nueva mentalidad frente a un problema añejo. El Libro Blanco señaló:

El desarrollo de los medios alternativos requiere de la formación de recursos humanos capaces de entender su uso y de operarlos correctamente.

115 http://www.scjn.gob.mx/PortalSCJN/RecJur/ReformaJudicial/LibroBlancoReform aJudicial/.

116 Idem. 
Esto supone alejarse de los paradigmas tradicionales que fomentan el litigio como el único mecanismo para resolver conflictos y formar abogados con una vocación orientada a resolver conflictos mediante el uso de otras alternativas... Introducir en los programas de estudio de las escuelas y facultades de derecho del país el estudio de los mecanismos alternos de solución de controversias. Esta educación debe contener tanto contenidos teóricos como prácticos para formar abogados capaces de entender la lógica y la operación de estos mecanismos. Se trata de dar a los jóvenes abogados una formación profesional orientada a resolver conflictos de manera eficiente y no únicamente a través del litigio judicial. ${ }^{117}$

Así, las escuelas de derecho deberían como mínimo incorporar como materia obligatoria la de los mecanismos alternativos de solución de controversias.

Más aún, considerando a la sociedad como usuaria de los mecanismos alternativos, la enseñanza y práctica del diálogo y la mediación deberían empezar en la educación primaria y secundaria; para sensibilizar a niños y niñas sobre actitudes y técnicas para resolver sus conflictos personales sin autoridades.

A largo plazo quizás todos aprendamos a manejar nuestros conflictos sin autoridades, y así tal vez el artículo 17 de nuestra Constitución ya no será necesario, podremos prescindir de tribunales y de un sistema legal. 